(2) Open Access Full Text Article

REVIEW

\title{
Artemether-lumefantrine in the treatment of uncomplicated Plasmodium falciparum malaria
}

This article was published in the following Dove Press journal:

Therapeutics and Clinical Risk Management

5 October 2009

Number of times this article has been viewed

\section{Stephan Ehrhardt Christian G Meyer}

Bernhard Nocht Institute for Tropical Medicine, Tropical Medicine Section, Hamburg, Germany
Correspondence: Dr Stephan Ehrhardt Bernhard Nocht Institute for Tropical Medicine, Bernhard Nocht Str. 74, 20359 Hamburg, Germany

Tel +494042818373

$\mathrm{Fax}+494042818394$

Email ehrhardt@bni-hamburg.de
Abstract: The World Health Organization strongly recommends artemisinin-based combination therapy (ACT) regimens for the treatment of uncomplicated Plasmodium falciparum malaria cases in endemic areas. Among the combinations of compounds that are available at present, excellent results have been obtained for the artemisinin derivative artemether, in a combination galenic preparation with lumefantrine (artemether-lumefantrine, AL). Here, the pharmacological properties and the therapeutic options of both substances are briefly reviewed and a cursory overview is given on recent trials that have compared the therapeutic effects of AL in the standard 6-dose regimen with other antimalarials and combinations. In order to ensure the most achievable and reliable adherence and compliance of children in the treatment of malaria, a dispersible formulation of AL is now attainable. Recent reports on the emergence of resistance to ACT regimens in Asia, however, are alarming.

Keywords: artemether, lumefantrine, malaria, Plasmodium falciparum, dispersible formulation, treatment, therapy

\section{Introduction}

According to the 2008 World Malaria Report of the World Health Organization, ${ }^{1}$ an estimated 247 million confirmed clinical episodes of malaria were documented in 2006 world-wide. However, and with respect to partly ineffective notification structures and the likelihood of underreporting cases in several malaria-endemic countries, the 5 th to 95th percentile uncertainty interval is wide and ranges from 189 million to 327 million cases. More than 880,000 fatalities due to Plasmodium falciparum malaria occurred in 2006, $91 \%$ of these in subSaharan Africa (SSA) and 85\% occurring among children under 5 years of age. ${ }^{1}$ Indeed, every 36 seconds a patient dies from malaria. The promotion of artemisinin-based combination therapy (ACT) regimens in recent years as, in terms of effectiveness and the low probability of rapidly evolving resistance to such combinations, a first-line strategy to treat uncomplicated falciparum malaria has under the pronounced advocacy of WHO officially been adopted in all but three countries (Cape Verde, Dominican Republic, French Guyana) and the territory of Swaziland by June 2008. This does, however, not necessarily imply strict routine use of ACT in countries which have officially adopted the WHO suggestion, and compounds to which resistance has emerged (eg, chloroquine, sulfadoxine-pyrimethamine) are still widely used.

The active components and the galenic formulations of ACT combinations vary. At present, the formulations artemether-lumefantrine (AL), artesunate-amodiaquine, artesunate-mefloquine and artesunate-sulfadoxine-pyrimethamine are available and 
recommended for treatment of malaria. Any preferential choice of one of these combinations in a region of intended implementation must critically depend both on the proven efficacy and the degree of parasite resistance to one of the components, either presently established or anticipated to manifest and spread in the foreseeable future. One of the most important issues of a memorandum of understanding that was endorsed and signed by the manufacturer Novartis and WHO in 2001 implies that AL $\left(\right.$ Coartem $\left.^{\circledR}\right)$ should be available at cost price in malaria-endemic areas.

\section{Artemisinin}

Artemisia annua (qīnghāo [青蒿], syn. sweet wormwood, sweet Annie, sweet sagewort, annual wormwood) is a medicinal herb native to temperate areas of Asia, but naturalized throughout the world. A. annua grows with a single stem about $2 \mathrm{~m}$ tall, has alternating branches with fern-like leaves, yellow flowers, and a dulcet fragrance of camphor. In central China, especially in the province Hubei, the stems of $A$. annua are still today used as food in a salad-like form. The product is a slightly bitter salad with strong acid overtones from the spiced rice vinegar used as marinade. It is considered a delicacy and is more expensive to buy than meat.

Extracts of $A$. annua have been in use medically, in particular in the treatment of feverish conditions, but also of hemorrhoids, by Chinese herbalists for centuries. The extracts and their potency are referred to in both the Recipes for 52 Kinds of Diseases which were unearthed from the Mawangdui Han Dynasty tomb in Changsha 168 B.C., ${ }^{2}$ and in the Zhou Hou Bei Ji Fang (中醫救治術精華; Handbook of Prescriptions for Emergency Treatments), written in 340 A.D. by Ge Hong of the Eastern Jin Dynasty. In 1596, artemisinin was mentioned by Li Shizhen as being effective in the treatment of malaria, although appropriate diagnostic tools for malaria were unvailable at that time.

The major active ingredient of $A$. annua, a sesquiterpene lactone (qinghaosu, artemisinin), was first isolated and chemically analyzed in detail in 1972 by Chinese researchers and its antimalarial activity was proven in both mice and primates. The active ingredient is found in the glandular trichomes of the plant leaves, stems and inflorescences, and congregates in the upper portions of the plants at new growth. It can be extracted with low boiling point solvents, eg, diethylether. Subsequently, in 1984 scientists at the Walter Reed Army Institute of Research crystallized the active component of A. annua. Artemesinin and its derivatives artemether, artesunate, arteether and others have since successfully been used to clear plasmodia, the causative infectious agents of malaria, from the blood more swiftly than do other drugs: artemisinin is indeed the fastest acting antimalarial available today. In particular, artesunate and artemether are known to clear parasitemias more rapidly than chloroquine, atovaquone-proguanil, mefloquine, quinine and sulfadoxine-pyrimethamine. Succesful and accelerated clearance applies, most importantly, also to otherwise resistant plasmodial strains. By inhibiting the maturation of plasmodial trophozoites, artemisinins efficiently prevent sequestration of parasitized erythrocytes in the microvasculature and, thus, impair disease progression. In contrast to the early belief that artemisinins modify the heme metabolic pathway we know now that the $P$. falciparum encoded sarcoplasmic-endoplasmic reticulum ATPase is most likely their true target. ${ }^{3}$

Clinically relevant and applicable artemisinins are rapidly metabolized in vivo to the biologically active dihydroartemisinin which has an elimination half-life of approximately 45 minutes. Artemisinins also lack the quinine-associated property to induce life-threatening hypoglycemia.

In addition to its strong antimalarial effectiveness, A. annua has also been claimed to exhibit considerable anticancer properties. The active ingredients appear to be selectively toxic to distinct breast cancer cells ${ }^{4}$ and some forms of prostate cancer, and exciting results have been reported from experiments with leukemia cells ${ }^{5}$ and other cancer cells. ${ }^{6}$ Furthermore, A. annua is effective in killing young adult worms in infections with the several species of the trematode Schistosoma, which may cause human schistosomiasis. ${ }^{7}$ Standard therapy regimens of these conditions with artemisinin derivatives have, in contrast to human malaria management, not yet been established. Respective options are, however, under study.

\section{Artemether}

As artemether is now the most widely used artemisinin derivative in the treatment of malaria, we will refer in the following to that particular derivative if not indicated otherwise.

Artemether is fat-soluble and readily absorbed within 2 hours after oral application. It is remarkably well tolerated, and peak serum levels occur within 1 hour of an oral dose and persist for up to 4 hours. The terminal phase elimination half-life is less than 1 hour. Co-administration with grapefruit juice and fat increases bioavailability. ${ }^{8}$ Artemether is demethylated by cytocrome P450 (CYP3A4)-mediated metabolic transformation. ${ }^{9}$ Dihydroartemisinin also exhibits antiparasite effects and is cleared rapidly, largely through the bile system. 
The inherent advantage of artemether, but also of all other artemisinins, is its rapid effect on all asexual erythrocytic stages of the malaria parasite and on the sexual gametocytes. It prevents gametocyte development by its effect on trophozoites and on early (stage I-III) gametocytes. ${ }^{10}$ In studies of more than 5000 malaria patients in Thailand it was convincingly demonstrated that gametocyte carriage occurred significantly less frequent among individuals who were treated with artemisinin derivatives than among those treated with mefloquine. ${ }^{11}$ Thus, apart from the extraordinary clinical benefit to the individual patient, efficient transmission of plasmodia is inhibited. ${ }^{12}$

The safety profile of artemether is remarkably good and the substance appears to be less toxic than quinine or chloroquine. Reports from clinical trials on serious adverse effects (SAEs) are scarce and include type 1 hypersensitivity reactions in about 1 out of 3,000 patients as well as drug-induced fever, hypotension, tinnitus, transient and clinically insignificant reticulocytopenia, neutropenia, elevated SGOT and SGPT plasma levels, bradycardia and ECG abnormalities. In particular, a prolongation of the QT interval has been observed. ${ }^{13}$ Gastrointestinal disturbances such as nausea, abdominal pain, diarrhea after oral application, dark urine, sweats, jaundice and somnolence and dizziness, pain at the site of the injection, skin reactions, and fever may occur rarely. All adverse events are reversible.

In animals, intramuscular injection of artemether can cause neurotoxicity, in particular neuronal damage in brain stem nuclei, ${ }^{14,15}$ most likely due to sustained blood concentrations of artemether after injection of the oily drug. Neurotoxic effects in mice are less pronounced when artemether is given orally, although higher blood concentrations are achieved via the parenteral route. ${ }^{16}$ However, these findings were not confirmed to occur in humans. ${ }^{17}$ Artemisinins have shown toxic potential, but no teratogenic potential, in animal models and are thus contraindicated in the first trimester of pregnancy if alternatives are obtainable. ${ }^{18}$

Overdosage of artemether has not been reported to date. Experiments with large doses of artemether, however, suggest the occurrence of cardiac irregularities, eg, prolongation of the QTc interval and arrhythmias (mostly tachycardia), and disturbances of the central nervous system. An ECG should be documented prior to the initiation of treatment in all cardiac patients. Clinicians who are confronted with situations of artemisinin overdosage should examine gait and balance as well as alterations of the ocular motility and of peripheral reflexes. An antidote to artemether is not at hand.
As the half-life of artemether is extremely short, a safe cure cannot be relied on unless multidose treatment has been applied, eg, for 7 days with plasma levels above the minimal parasitocidal concentration. The use of artemisinins in monotherapy of malaria is, however, not recommended as it is associated with high incidences of recrudescent infection. In addition, combined treatment with a second drug is critically important in order to prevent the development of artemisinin resistance. The WHO has announced in 2006 that 13 pharmaceutical companies have agreed to comply with the prudent recommendation to phase out single-drug artemisinin medicines for oral malaria treatment. Complying companies include the leading producers of high quality artemisininbased substances. They will now focus their marketing efforts primarily on combinatory drugs (artemisinin-based combination therapy, ACT).

\section{Resistance to artemisinins}

In experimental laboratory settings, the induction of persistent high-level resistance to artemisinins in $P$. falciparum is difficult to achieve. Rodent malarias, but also $P$. falciparum with a 5- to 10-fold reduced susceptibility, could be selected in vitro. ${ }^{19}$ P. falciparum multidrug resistance gene 1 (Pfmdr 1 ) is associated with slight but significant reductions in susceptibility to artemisinins. ${ }^{20}$ In vitro data from French Guyana and Senegal indicate that inhibitory concentrations (IC) 50 values as high as $117 \mathrm{nmol} / \mathrm{L}$ and $45 \mathrm{nmol} / \mathrm{L}$, respectively, were associated with mutations (S769N) in the SERCA-type PfATPase6. ${ }^{21}$ Data were collected in areas of unrestrained and unsupervised oral artemisinin application. Data that come from Cambodia and its border to neighboring Thailand are of concern as well. In this cradle area of drug resistance development and multidrug-resistant $P$. falciparum, treatment failure to artesunate-mefloquine as well as to AL already exceeds $10 \%,{ }^{22}$ whereby it is unclear whether resistance to partner compounds of the artemisinins play a prominent role. ${ }^{23}$ Other investigators have found, in the very same area, a persistent high sensitivity of $P$. falciparum to artesunate-mefloquine, but steadily decreasing parasitological responses to artesunate, and an increase in gametocyte carriage of patients. ${ }^{24}$ Nevertheless, artemisinin derivatives have been used in this region for more than 30 years now and, most likely, exerted considerable cumulative evolutionary pressure on P. falciparum. Until now, in vitro resistance of parasite isolates appears to be inducible. ${ }^{20} \mathrm{~A}$ most recent alarming study from the Thai-Cambodian border raises, however, concern in this matter and clearly indicates the urgent need of appropriate containment measures. ${ }^{25}$ 
Table I Countries by WHO region which have adopted artemether-lumefantrine (AL) as first-line drug policy for the treatment of uncomplicated falciparum malaria ${ }^{18}$

\begin{tabular}{|c|c|}
\hline WHO region & Country \\
\hline Africa & 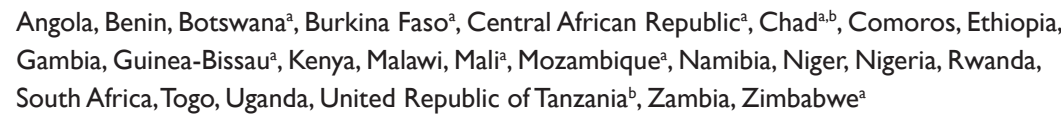 \\
\hline Western Pacific & Papua New Guinea ${ }^{a}$, Philippines ${ }^{\mathrm{a}}$, Vanuatu ${ }^{\mathrm{a}}$ \\
\hline
\end{tabular}

aPolicy adopted but not fully implemented. ${ }^{\mathrm{b}} \mathrm{AL}$ adopted, but not exclusively; other ACTs in use as well.

The spread of artemisinin resistance westwards has also been addressed. ${ }^{26}$ Discrepancies between in vivo and in vitro data require careful exploration. Parasite isolates from most other parts of the world are still highly sensitive to artemisinins. We are, however, expecting now the first data sets from Kenya where corresponding studies on artemisinin resistance are being performed. In vitro, the median IC50 for dihydroartemisinin and artesunate are usually below $10 \mathrm{nmol} / \mathrm{L}$. IC50s for artemether and artemisinin are typically 2 to 3 times and 5 to 10 times higher, respectively. ${ }^{20}$

To delay the imminent emergence of resistance, artemisinins are now combined with longer-acting drugs, in particular with amodiaquine, mefloquine, sulfadoxinepyrimethamine or with lumefantrine. The addition of longacting drugs to artemisinins causes the elimination of residual parasites that were not readily disrupted by the fast-acting artemisinin. The combinatory drug that has been studied best so far is lumefantrine.

\section{Lumefantrine}

Lumefantrine (previously referred to as benflumetol) is a substance with distinct blood schizontocidal activities against a wide range of plasmodia, including $P$. falciparum and all other human plasmodia. Lumefantrine, a fluorene (benzindene) derivative (a-(dibutylaminomethyl)2,7-dichloro-9-(p-chlorobenzylidene)-5-fluorenemethanol), is an aryl-amino alcohol with intriguing similarities to other antimalarials (quinine, halofantrine, mefloquine). It has, however, and in contrast to these substances, never routinely been used as monotherapy in malaria. Lumefantrine originates, as does artemether, from malaria research in China. It was synthesized in the 1970 s by the noncommercial Academy of Military Medical Sciences in Beijing ${ }^{27}$ and its effectiveness against all Plasmodium species that are pathogenic to humans has been documented and evaluated in several studies. ${ }^{9}$

Lumefantrine is highly lipophilic and resorption commences approximately two hours after administration. Peak plasma levels are found 6 to 8 hours after administration, whereby plasma levels may vary considerably between individuals. ${ }^{28}$ Concomitant consumption of food, in particular the intake of fat at a minimum amount of about $1.2 \mathrm{~g} /$ dose of lumefantrine, ${ }^{29}$ enhances the bioavailability of both artemether and lumefantrine by the factors 2 and 16, respectively. Concerns that fat contents of meals in sub-Saharan Africa might not suffice for ample bioavailability of AL with convincing cure rates have been addressed in a recent review article and have been contradicted. ${ }^{30}$ However, an anecdotal case report indicates that insufficient fat intake or even starvation may result in treatment failure. ${ }^{31}$

The precise mode of the efficacy of lumefantrine on plasmodia is not fully understood. It results, most likely, from the interaction of heme, a degradation product of the hemoglobin metabolism, with the active ingredients in the digestive vacuole of the malaria parasite. It may, however, also interfere with the synthesis of nucleic acids and proteins. The activity of lumefantrine is slower than that of artemisinins and the recrudescence rate is low when the substance is given as recommended. Lumefantrine binds strongly to lipoproteins and has a terminal phase elimination half-life of approximately 86 hours. ${ }^{9}$ In dogs and rats, a direct glucuronidation takes place in vivo after oxidative biotransformation. In human liver microsomes, lumefantrine is N-dibutylated by CYP3A 42 and, in vitro, lumefantrine inhibits at appropriate plasma concentrations significantly the activity of CYP2D6.

The pharmacokinetic properties of lumefantrine are reminiscent of characteristics of halofantrine, with variable oral bioavailability profiles, considerable augmentation of oral bioavailability through concomitant consumption of fat, and a terminal elimination half-life of 2 to 3 days in healthy volunteers and 4 to 6 days in patients with clinically relevant P. falciparum infections. ${ }^{33}$

\section{Artemether-lumefantrine: the fixed-dose formulation}

The rationale of using ACT is as follows: different half-lives of ACT compounds, with extremely short half-lives of 
artemisinin derivatives and long half-lives of the partner drugs cause a pharmacokinetic imbalance. The rapid onset of action of artemisinins reduces the biomass of the parasite within a short period of time. The remaining parasites are subject to elimination through the partner drug. This mode of action has proven highly effective. It implies, however, that the efficacy of ACTs critically depends on the parasite's sensitivity to the non-artemisinin partner drug. In order to minimize the development of ACT resistance, fixed co-formulations are superior to two separate or co-blistered drugs, as fixed combinations explicitly exclude artemisinin monotherapy. Currently, 100 million ACT treatments are prescribed per year, approximately $75 \%$ of them with AL. $\mathrm{AL}$ is now registered in 79 countries. The second largest share of the market has artesunate-amodiaquine as a co-blistered formulation which is expected to be replaced in due time by a fixed-dose combination produced by Sanofi-Aventis. ${ }^{34}$ Given that approximately 300 million malaria treatments are needed annually, the number of ACTs to be distributed could readily double by 2012 . Taking into account the current absence of clinically significant resistance to these ACTs outside Cambodia and Thailand, they are likely to be the most commonly used ACTs for the next few years to come.

The combination of artemether with lumefantrine was developed in China and first evaluated in the 1960s. Based on the good results, Novartis was involved in the production and distribution of $\mathrm{AL}$ as Coartem $^{\circledR}$ or Riamet ${ }^{\circledR}$. It was the first fixed-dose antimalarial drug combination of an artemisinin derivative with an unrelated co-substance, in terms of biochemical and pharmacological properties. First, tablets containing 20/120 mg AL were introduced as a 4-dose regimen (total dose: $80 / 480 \mathrm{mg} \mathrm{AL}$ ) to be administered at $0,8,24$ and 48 hours of treatment. Pharmacokineticpharmacodynamic (PK-PD) data, however, suggested that the main PK determinant of cure was either the area under the actual plasma lumefantrine concentration time curve (AUC) or, as a proxy, the concentration of lumefantrine at day $7 .{ }^{27}$ Lumefantrine plasma concentrations at day 7 of $>500 \mathrm{ng} / \mathrm{mL}$ are required to result in cure rares of more than $90 \%$, but such success could not be reproducibly and reliably achieved with the 4-dose regimen. To increase the AUC, a 6-dose regimen was then tested and proved highly effective and well tolerated in adults when each 4 tablets were given at $0,8,24,36,48$ and 60 hours of the treatment course. ${ }^{35}$ When comparing the 6 -dose regimen over 60 hours with the 6 -dose regimen over 96 hours with tablets given at $0,8,24,48,72$ and 96 hours, the 28-day cure rates were still slightly higher. ${ }^{35}$
In children, appropriately bodyweight-adjusted AL doses are recommended. Children with weights of $\geq 5 /<15 \mathrm{~kg}$, $\geq 15 /<25 \mathrm{~kg}$ and $\geq 25 /<35 \mathrm{~kg}$ should receive 1,2 and 3 tablets, respectively, per time point. Demographic variables such as gender, body weight, age and ethnicity do not appear to affect the pharmacokinetics of AL. If vomiting occurs within one hour of administration, an equal dose of $\mathrm{AL}$ should be given again.

\section{Artemether-lumefantrine: drug interactions}

Administration of AL together with ketoconazole, a potent CYP3A4 inhibitor, resulted in elevated plasma levels of artemether, dihydroartemisinin and lumefantrine. These increases were, however, considered clinically insignificant, ${ }^{32}$ as were decreases in the lumefantrine AUC when mefloquine, a CYP3A4 substrate as well, was simultaneously given to healthy individuals. ${ }^{36}$ As antiretroviral drugs are powerful modulators of CYP enzymes, validated pharmacokinetic data on their interactions with AL are now urgently needed. Patients who are undergoing antiretroviral treatment should be examined regularly during a treatment course with AL.

When switching from AL to quinine during a treatment course, the long elimination half-life of lumefantrin must be considered and careful ECG monitoring is essential. Pretreatment with mefloquine does not modify the plasma concentration of artemether or the ratio artemetherdihydroartemisinin. However, a significant decline of plasma lumefantrine levels may occur, most likely due to a mefloquine-induced decreased resorption that is induced by diminished production and output of bile.

\section{Artemether-lumefantrine: side effects, cautions and contraindications}

AL is tolerated very well in the majority of cases. A tolerability superior to that of mefloquine alone or to the combination of mefloquine with artesunate has repeatedly been observed..$^{37,38}$ Adverse effects that were reported include gastrointestinal irritations, headache, dizziness, fatigue, sleep disturbances, rash, palpitations, myalgia and arthralgia. ${ }^{39}$ Evidence of cardiotoxicity, which may be expected due to structural similarities of lumefantrine with mefloquine, quinine, and halofantrine, is weak. In fact, in healthy volunteers as well as in patients, clinical studies could not demonstrate significant changes in the QTc interval, or a correlation between plasma lumefantrine levels and QTc intervals..$^{40,41}$ One study has 
indicated a modestly increased risk of QTc prolongation when AL was given to healthy individuals together with quinine intravenously. ${ }^{32}$ Data on cardiotoxicity of artemisinin derivatives in general, and of artemether in particular, have shown clinically insignificant ECG abnormalities in $<1.3 \%$ of more than 2600 patients who were suveyed. ${ }^{13}$ However, as in several studies asymptomatic prolongations of the QTc intervals have been described, the manufacturing company has decided to restrain from recommending AL for patients with recognized cardiac arrhythmias and for patients who are on medications potentially affecting the QTc interval. Studies of patients with renal or hepatic impairment have not been conducted so far.

Initial reports on irreversible audiometric changes in humans treated with AL have raised concern. ${ }^{42}$ Further careful evaluation in a randomized trial, however, has not confirmed any detrimental effects of standard oral regimens of AL on peripheral hearing or brainstem auditory pathways in patients with falciparum malaria. ${ }^{43}$

According to the manufacturer, approximately 20 distinct SAEs were observed in more than 1800 patients treated. These include severe anemia in children, pneumonia, hepatitis, and one case of hemolytic anemia and others, all of which could even have been caused by the malaria infection itself. ${ }^{13}$ Because of the unavailability of validated data, AL should not be given to pregnant or breast-feeding women and clinicians should use AL in these patients only when alternatives are either not obtainable or contraindicated. ${ }^{18}$ This applies also to children with body weights less than $5 \mathrm{~kg}$. Overall, the tolerability and safety profile of AL is favorable, while drug interactions should be subject to clinical notice and trigger further research.

\section{Procurement of artemether- lumefantrine by WHO}

AL has been included in the WHO Model List of Essential Medicines for adults and children (http://www.who.int/ medicines/publications/essentialmedicines/en/), a list of essential medicines compiled by a group of independent experts who select basically essential drugs according to their public health relevance, evidence of efficacy and safety, and competitive cost-effectiveness. Novartis, the manufacturer of AL, and WHO have formally agreed to collaborate in order to increase the access to AL in developing countries. Through this collaboration, WHO intends to achieve a broad and equitable availability of safe and effective malaria treatment and, in addition, contribute to the control of drug resistance. In its function as a technical adviser to member states, WHO wants to contribute to both national drug policy changes and rational drug use.

Despite strong efforts to modify the properties and galenics of AL, it still has a limited shelf-life of 24 months only. This requires efficient distribution infrastructures on all levels of health care systems. The problem applies in particular to those developing countries which have adopted AL as first-line drug for the treatment of uncomplicated falciparum malaria. These countries face the challenge of supplying AL to remote primary health care facilities and to assure correct storage of sufficient amounts of the medicines.

Most recent data indicate that AL tablets may be chemically and physically stable well beyond the stated shelflife even under tropical, ie, warm, conditions. ${ }^{44}$ These data should, however, not pave the way for a permissive attitude about the stability of AL tablets, but rather lead to thorough investigation and examinations and, if possible, chemical and galenic improvement.

UNICEF and other official agencies as well as nongovernmental organizations have established direct procurement agreements with Novartis to supply AL at the cost that was negotiated by WHO. As a direct consequence, a smaller proportion of AL was procured through WHO in $2007 .^{1}$

\section{Soluble formulations of artemether- lumefantrine for children}

A 3-day, 6-dose regimen of AL is efficacious and safe both in adults and children. ${ }^{45,46}$ Infants and children can safely be treated when weighing $5 \mathrm{~kg}$ or more. AL was found to have an efficacy of $90 \%$ or more in African children at day 28 of treatment. This was even true under unsupervised outpatient conditions when nutritional advice, namely intake with fatty food, was given. ${ }^{47}$ Young children are, especially if they are sick, not able to swallow the AL tablets. In everyday practice, crushing of the tablets and administering them with water is the typical solution of this problem. This, however, results in a bitter tasting solution, potentially compromising tolerability and compliance. To overcome these problems, dispersible tablets (Coartem ${ }^{\circledR}$ Dispersible) have been tailored for exclusive pediatric use by Novartis in collaboration with Medicines for Malaria Venture (MMV). The main features of Coartem $^{\circledR}$ were maintained as far as possible, in particular the strength of the dosage (20 mg A/120 mg L) per dispersible tablet. The sweetened and cherry-flavored dispersible tablets have to be added to a small amount of water and administered without delay orally once disintegrated to a suspension. Rinsing the water glass is recommended to ensure complete administration. 
Table 2 Therapeutic effects of artemether-lumefantrine (6-dose regimen;standard tablets of 20/I20 mg AL) in children in malaria-endemic areas with uncomplicated falciparum malaria - comparison to other antimalarial compounds

\begin{tabular}{|c|c|c|c|c|c|}
\hline Drugs tested vs AL & Country & $\mathbf{n}$ & Main conclusion & Score $^{a}$ & Reference \\
\hline AS-SMP-PYR & $\begin{array}{l}\text { Cameroon, Mali, } \\
\text { Rwanda, Sudan }\end{array}$ & 1,384 & $\begin{array}{l}\text { Similar effectiveness, efficacy } \\
\text { and tolerability }\end{array}$ & $+1-$ & 52 \\
\hline AQ-AS & Ghana & 246 & $\begin{array}{l}\text { Equal clinical and parasitological } \\
\text { responses; more late clinical } \\
\text { failures with AL; AL less well } \\
\text { accepted }\end{array}$ & - & 53 \\
\hline $\begin{array}{l}\text { CQ-SUL-PYR } \\
\text { AS-SUL-PYR } \\
\text { DHA-PIP }\end{array}$ & Papua New Guinea & 482 & AL most effective & + & 54 \\
\hline DHA-PIP & Kenya & 146 & $\begin{array}{l}\text { Faster parasite clearance } \\
\text { with } \mathrm{AL}\end{array}$ & + & 55 \\
\hline AS-MQ & Mali & 470 & $\begin{array}{l}\text { Similar cure rates; more new } \\
\text { infections after treatment } \\
\text { with } \mathrm{AL}\end{array}$ & - & 56 \\
\hline AS-AQ & Ghana & 227 & $\begin{array}{l}\text { Both equally effective and well } \\
\text { tolerated }\end{array}$ & $+1-$ & 57 \\
\hline $\begin{array}{l}\text { AS-AQ } \\
\text { AS-CPG-DAP }\end{array}$ & Ghana & 534 & $\begin{array}{l}\text { Similar effectiveness and } \\
\text { tolerability }\end{array}$ & $+1-$ & 58 \\
\hline DHA-PIP & Uganda & 414 & $\begin{array}{l}\text { Similar efficacy; higher risk of } \\
\text { reinfection in AL group, higher } \\
\text { risk of gametocytemia in } A L \\
\text { group; equally well tolerated }\end{array}$ & - & 59 \\
\hline AS-AQ & Nigeria & 132 & Equal efficacy and safety & $+1-$ & 60 \\
\hline AS-AQ & Tanzania & 157 & $\begin{array}{l}\text { Similar efficacy after PCR } \\
\text { adjustment }\end{array}$ & & 61 \\
\hline $\begin{array}{l}\text { AQ-SUL-PYR } \\
\text { DHA-PIP }\end{array}$ & Burkina Faso & 559 & $\begin{array}{l}\text { Similar risk of genotype- } \\
\text { adjusted treatment failure, } \\
\text { equally well tolerated }\end{array}$ & $+1-$ & 62 \\
\hline SUL-PYR & Nepal & 99 & $\begin{array}{l}\text { AL more effective than } \\
\text { comparison drug }\end{array}$ & + & 63 \\
\hline AQ-SFL-PYR & Nigeria & 181 & $\begin{array}{l}\text { Similar efficacy, tolerability, and } \\
\text { gametocyte-carrier rate; faster } \\
\text { parasite clearance in the AL } \\
\text { group }\end{array}$ & + & 64 \\
\hline AS-SUL-PYR & Sudan & 160 & Both regimens highly effective & $+1-$ & 65 \\
\hline $\begin{array}{l}\text { AS-AQ } \\
\text { AS-MQ } \\
\text { AQ-SUL-PYR }\end{array}$ & Senegal & 955 & $\begin{array}{l}\text { All combinations after PCR } \\
\text { correction similarly effective } \\
\text { and well tolerated }\end{array}$ & $+1-$ & 66 \\
\hline DHA-PIP & Uganda & 421 & $\begin{array}{l}\text { Higher risk of recurrent } \\
\text { parasitemia and gametocytemia } \\
\text { in the } A L \text { group }\end{array}$ & - & 67 \\
\hline $\begin{array}{l}\text { AQ-SUL-PYR } \\
\text { AQ-AS }\end{array}$ & Uganda & 601 & $\begin{array}{l}\text { AL was the most efficacious } \\
\text { treatment }\end{array}$ & + & 68 \\
\hline DHA-PIP & Indonesia & 774 & $\begin{array}{l}\text { Both equally safe and effective } \\
\text { after PCR correction; higher } \\
\text { risk of reinfection in the AL } \\
\text { group }\end{array}$ & - & 69 \\
\hline AQ-SUL-PYR & Burkina Faso & 521 & AL less effective & - & 70 \\
\hline AQ-SUL-PYR & Rwanda & 500 & $\begin{array}{l}\text { AL more efficacious than } \\
\text { comparison drug }\end{array}$ & + & 71 \\
\hline MQ-AS & Cambodia & 190 & $\begin{array}{l}\text { Lower cure rates in AL, } \\
\text { possibly due to low levels } \\
\text { of lumefantrine in blood or } \\
\text { lumefantrine resistance }\end{array}$ & - & 23 \\
\hline
\end{tabular}


Table 2 (Continued)

\begin{tabular}{|c|c|c|c|c|c|}
\hline Drugs tested vs AL & Country & $\mathbf{n}$ & Main conclusion & Score $^{a}$ & Reference \\
\hline $\begin{array}{l}\text { AS-SUL-PYR } \\
\text { AS-AQ }\end{array}$ & Republic of Congo & 298 & $\begin{array}{l}\text { Better efficacy and fewer reinfections in } \\
\text { the AL group }\end{array}$ & + & 72 \\
\hline AS-SMP-PYR & Mali & 606 & $\begin{array}{l}\text { Same efficacy/safety profile as AL; both } \\
\text { well tolerated }\end{array}$ & $+1-$ & 73 \\
\hline AS-AQ & Uganda & 408 & $\begin{array}{l}\text { Equal efficacy; AL superior in preventing } \\
\text { new infections }\end{array}$ & + & 74 \\
\hline AS-AQ & Angola & 137 & Equal efficacy & $+1-$ & 75 \\
\hline AS-AQ & Nigeria & 119 & Equally high efficacy and tolerability & $+1-$ & 76 \\
\hline AS-SUL-PYR & Sudan & 143 & Equally high efficacy and tolerability & $+1-$ & 77 \\
\hline AS-MQ & Thailand & 490 & Equally high efficacy & $+1-$ & 78 \\
\hline AS-AQ & Tanzania (Zanzibar) & 408 & $\begin{array}{l}\text { Equal efficacy; AL superior in preventing } \\
\text { new infections }\end{array}$ & + & 79 \\
\hline $\begin{array}{l}\text { CQ-SUL-PYR } \\
\text { AS-MQ }\end{array}$ & Bangladesh & 364 & $\begin{array}{l}\text { Both } \mathrm{ACT} \text { s effective, well tolerated, } \\
\text { reduced gametocyte carriage }\end{array}$ & $+1-$ & 80 \\
\hline $\begin{array}{l}\text { CQ } \\
\text { SUL-PYR AS-AQ }\end{array}$ & Ghana & 168 & $\begin{array}{l}\text { Rapid fever, parasite and gametocyte } \\
\text { clearance in the studied ACTs }\end{array}$ & $+1-$ & 81 \\
\hline CQ-SUL-PYR & The Gambia & 497 & $\begin{array}{l}\text { AL reduced risk of gametocyte-carriage } \\
\text { and gametocyte density post-treatment }\end{array}$ & + & 82 \\
\hline $\begin{array}{l}\text { AQ AQ-SUL-PYR } \\
\text { AS-AQ }\end{array}$ & Tanzania & 1811 & $\begin{array}{l}\text { Best effectiveness and least recrudes- } \\
\text { cences in the AL group }\end{array}$ & + & 83 \\
\hline AS-MQ & $\begin{array}{l}\text { Lao People's Democratic } \\
\text { Republic }\end{array}$ & 108 & Equally high efficacy and tolerability & $+1-$ & 84 \\
\hline $\begin{array}{l}\text { CQ-SUL-PYR } \\
\text { AS-MQ }\end{array}$ & $\begin{array}{l}\text { Lao People's Democratic } \\
\text { Republic }\end{array}$ & 330 & Both ACTs highly effective & $+1-$ & 85 \\
\hline AS-MQ & Thailand & 219 & Similar efficacy and tolerability & $+1-$ & 86 \\
\hline AS-MQ & Thailand & 200 & $\mathrm{AL}$ equally effective but better tolerated & + & 87 \\
\hline
\end{tabular}

Notes: Randomized, comparative efficacy and/or efficiency trials found in PubMed when search terms "artemether AND lumefantrine" were entered are included in the table. Only trials that were published in English are considered.

aScoring refers to the comparisons of $\mathrm{AL}$ with other components;,,,$+-+- \mathrm{AL}$ superior, inferior, equal, respectively, to the comparison drugs; ${ }^{\mathrm{b}} \mathrm{children}$ and adults.

Abbreviations: AL, artemether-lumefantrine; ACT, artemisinin combination therapy; n, number of randomized study participants; AS, artesunate; CPG, chlorproguanil; CQ, chloroquine; DAP, dapsone; DHA, dihydroartemisinin; MQ, mefloquin; PIP, piperaquine; PYR, parimethamine; SFL, sulfalene; SMP, sulphamethoxyPyrazine; SUL, sulfadoxine.

In a randomized, multicenter, non-inferiority, investigator-masked clinical trial including 899 children in Benin, Mali, Kenya, Tanzania/Zanzibar and Mozambique, the 28-day parasitological cure rate (PCR corrected) in the per-protocol analysis was $97.8 \%$ (95\% confidence interval [CI], 96.3 to 99.2 ) for dispersible tablets and $98.5 \%$ (95\% CI, 97.4 to 99.7) for the administration of crushed tablets. ${ }^{48}$ In the intention-to-treat analysis of this study, these figures were $95 \%$ and $96.2 \%$, respectively. The safety profile of dispersible AL tablets also equals that of the standard tablets. The costs of this formulation are identical to those of the standard formulation. Several African countries have already approved the dispersible galenics of AL. Novartis has now applied for the inclusion of Coartem ${ }^{\circledR}$ Dispersible in the $W H O$ Model List of Essential Medicines for Children, a step that appears reasonable and justified.

Another soluble formulation, a dry powder containing $15 \mathrm{mg}$ Artemether and $90 \mathrm{mg}$ Lumefantrine per $5 \mathrm{~mL}$ of liquid after reconstitution (Co-Artesiane ${ }^{\circledR}$; Dafra Pharma), was successfully tested against AL standard tablets in a randomized, controlled, open-label trial in Kenya. ${ }^{49}$ The results of this study did also not indicate any differences in cure rates or safety, though they had a lower statistical power to do so.

\section{Trials on the efficacy of artemether- lumefantrine in children}

Table 2 lists clinical trials from Africa and Asia in which the therapeutic effects and/or the tolerability and/or the risk of reinfections of the 6-dose AL regimen with standard tablets in children in malaria-endemic areas with uncomplicated falciparum malaria were compared to that of other antimalarials. The studies listed in Table 2 are based on a NCBI-PubMed review with the search terms "artemether AND lumefantrine" and did not adhere to the stringent selection criteria which are applied for the meta-analyses of the Cochrane Infectious Diseases Group Specialized 
Register. Notably, in several studies only small numbers of participants were enrolled.

Although the conclusions that came from the various comparative studies are partly inconsistent and, in some cases, dependent on inherent differences in reporting, they clearly demonstrate the favorable tolerability, high efficacy and adequate parasitological responses to ACT in general and in particular to the standard 6-dose regimen. In the majority of the comparisons, the overall evaluation of AL appears superior to the comparison substances. In those studies where AL was rated inferior to the comparison drug or drug combination it is worth to note that in all studies, except one, artemisinin derivatives were part of the comparison. The overall good effectiveness and tolerability is in line with the 2005 Cochrane Database Systematic Review, ${ }^{50}$ which concludes that, after evaluation of 9 clinical trials, the 6-dose regimen of AL appears to be more effective than antimalarial regimens not containing artemisinin derivatives.

\section{Conclusion}

Although resistance now appears to be emerging, ACT treatment is still the best choice that we have at present for the treatment of uncomplicated $P$. falciparum malaria, both in disease of children and adults. It is sufficiently well tolerated and effective and some degree of resistance against the constituent components has only recently been reported. This situation certainly requires attentive monitoring and the development of containment strategies. The dispersible formulation of AL for use in pediatric malaria is an important and favorable improvement, as it will certainly enhance the compliance of affected children and of the parents who care for them. However, we are desperately waiting for the effective (at best $99 \%$ or so) malaria vaccine, which is not in sight yet. Recent encouraging observations on the RTS,S/AS01E vaccine that is still undergoing evaluation in several regions show an adjusted efficacy rate of 53\%. ${ }^{51}$ Until comprehensive coverage with an effective vaccine we have to cope with and explore and improve all available and attainable preventive and therapeutic options in order to reduce the intolerable burden of malaria.

\section{Disclosures}

The authors have no conflicts of interest to disclose.

\section{References}

1. World malaria report 2008. World Health Organization. 2008. Geneva. Available from: http:/www.who.int/malaria/wmr2008/

2. Li Y, Wu YL. An over four millennium story behind qinghaosu (artemisinin) - a fantastic antimalarial drug from a traditional Chinese herb. Curr Med Chem. 2003;21:2197-2230.
3. Eckstein-Ludwig U, Webb RJ, Van Goethem ID, et al. Artemisinins target the SERCA of Plasmodium falciparum. Nature. 2003;424:957-961.

4. Li PC, Lam E, Roos WP, Zdzienicka MZ, Kaina B, Efferth T. Artesunate derived from traditional Chinese medicine induces DNA damage and repair. Cancer Res. 2008;68:4347-4351.

5. Zhou HJ, Wang WQ, Wu GD, Lee J, Li A. Artesunate inhibits angiogenesis and downregulates vascular endothelial growth factor expression in chronic myeloid leukemia K562 cells. Vascul Pharmacol. 2007;47:131-138.

6. Oh S, Kim BJ, Singh NP, Lai H, Sasaki T. Synthesis and anti-cancer activity of covalent conjugates of artemisinin and a transferrin-receptor targeting peptide. Cancer Lett. 2009;8(274):33-39.

7. Keiser J, Utzinger J. Artemisinins and synthetic trioxolanes in the treatment of helminth infections. Curr Opin Infect Dis. 2007;20:605-612.

8. van Agtmael MA, Gupta V, van der Wösten TH, Rutten JP, van Boxtel CJ. Grapefruit juice increases the bioavailability of artemether. Eur J Clin Pharmacol. 1999;55:405-410.

9. Nosten F, White NJ. Artemisinin-based combination treatment of falciparum malaria. Am J Trop Med Hyg. 2007;77:181-192.

10. Mehra N, Bhasin VK. In vitro gametocytocidal activity of artemisinin and its derivatives on Plasmodium falciparum. Jpn J Med Sci Biol. 1993;46:37-43.

11. Adjuik M, Babiker A, Garner P, Olliaro P, Taylor W, White N; International Artemisinin Study Group. Artesunate combinations for treatment of malaria: meta-analysis. Lancet. 2004;363(9402):9-17.

12. Rosenthal PJ. Artesunate for the treatment of severe falciparum malaria. N Engl J Med. 2008;358:1829-1836.

13. Taylor WR, White NJ. Antimalarial drug toxicity: a review. Drug Saf. 2004;27:25-61.

14. Brewer TG, Peggins JO, Grate SJ, et al. Neurotoxicity in animals due to arteether and artemether. Trans R Soc Trop Med Hyg. 1994;88 Suppl 1: S33-S36.

15. Brewer TG, Grate SJ, Peggins JO, et al. Fatal neurotoxicity of arteether and artemether. Am J Trop Med Hyg. 1994;51:251-259.

16. Nontprasert A, Pukrittayakamee S, Dondorp AM, Clemens R, Looareesuwan S, White NJ. Neuropathologic toxicity of artemisinin derivatives in a mouse model. Am J Trop Med Hyg. 2002;67:423-429.

17. Hutagalung R, Htoo $\mathrm{H}$, Nwee $\mathrm{P}$, et al. A case-control auditory evaluation of patients treated with artemether-lumefantrine. Am J Trop Med Hyg. 2006;74:211-214.

18. World Health Organization. Guidelines for the treatment of malaria. WHO; 2006. Geneva.

19. Hunt P, Afonso A, Creasey A, et al. Gene encoding a deubiquitinating enzyme is mutated in artesunate- and chloroquine-resistant rodent malaria parasites. Mol Microbiol. 2007;65:27-40.

20. White NJ. Qinghaosu (artemisinin): the price of success. Science. 2008;320:330-334.

21. Jambou R, Legrand E, Niang M, et al. Resistance of Plasmodium falciparum field isolates to in-vitro artemether and point mutations of the SERCA-type PfATPase6. Lancet. 2005;366:1960-1963.

22. Denis MB, Tsuyuoka R, Poravuth Y, et al. Surveillance of the efficacy of artesunate and mefloquine combination for the treatment of uncomplicated falciparum malaria in Cambodia. Trop Med Int Health. 2006a;11:1360-1366.

23. Denis MB, Tsuyuoka R, Lim P, et al. Efficacy of artemether-lumefantrine for the treatment of uncomplicated falciparum malaria in northwest Cambodia. Trop Med Int Health. 2006;11:1800-1807.

24. Carrara VI, Zwang J, Ashley EA, et al. Changes in the treatment responses to artesunate-mefloquine on the northwestern border of Thailand during 13 years of continuous deployment. PLOS ONE. 2009;4:e4551.

25. Dondorp AM, Nosten F, Yi P, et al. Artemisinin Resistance in Plasmodium falciparum Malaria. N Engl J Med. 2009;361:455-467.

26. Noedl H, Socheat D, Satimai W. Artemisinin-Resistant Malaria in Asia. N Engl J Med. 2009;361:540-541.

27. World Health Organization. Practical chemotherapy of malaria. Report of a WHO Scientific Group. WHO Tech Rep Ser 805, WHO, Geneva; 1990:124-126. 
28. White NJ, van Vugt M, Ezzet F. Clinical pharmacokinetics and pharmacodynamics and pharmacodynamics of artemether-lumefantrine. Clin Pharmacokinet. 1999;37:105-125.

29. Ashley EA, Stepniewska K, Lindegårdh N, et al. How much fat is necessary to optimize lumefantrine oral bioavailability? Trop Med Int Health. 2007;12:195-200.

30. Premji ZG, Abdulla S, Ogutu B, et al. The content of African diets is adequate to achieve optimal efficacy with fixed-dose artemetherlumefantrine: a review of the evidence. Malar J. 2008;7:244.

31. Mizuno Y, Kato Y, Kudo K, Kano S. First case of treatment failure of artemether-lumefantrine in a Japanese traveler with imported falciparum malaria. Jpn J Infect Dis. 2009;62:139-141.

32. Lefèvre G, Carpenter P, Souppart C, Schmidli H, McClean M, Stypinski D. Pharmacokinetics and electrocardiographic pharmacodynamics of artemether-lumefantrine (Riamet) with concomitant administration of ketoconazole in healthy subjects. Br J Clin Pharmacol. 2002; $54: 485-492$

33. Lefèvre G, Thomsen M. Clinical pharmacokinetics of artemether and lumefantrine $\left(\right.$ Riamet $\left.^{\mathbb{\circledR}}\right)$. Clin Drug Invest. 1999;18:467-480.

34. Olliaro P, Wells T. The Global Portfolio of New Antimalarial Medicines Under Development. Clin Pharmacol Ther. 2009;85: 584-595.

35. van Vugt, Wilairatana P, Gemperli B, et al. Efficacy of six doses of artemether-lumefantrine (benflumetol) in multidrug-resistant Plasmodium falciparum malaria. Am J Trop Med Hyg. 1999; 60:936-942.

36. Lefèvre G, Bindschedler M, Ezzet F, Schaeffer N, Meyer I, Thomsen MS. Pharmacokinetic interaction trial between co-artemether and mefloquine. Eur J Pharm Sci. 2000;10:141-151.

37. Looareesuwan $\mathrm{S}$, Wilairatana $\mathrm{P}$, Chokejindachai $\mathrm{W}$, et al. A randomized, double-blind, comparative trial of a new oral combination of artemether and benflumetol (CGP 56697) with mefloquine in the treatment of acute Plasmodium falciparum malaria in Thailand. Am J Trop Med Hyg. 1999;60:238-243.

38. van Vugt M, Brockman A, Gemperli B, et al. Randomized comparison of artemether-benflumetol and artesunate-mefloquine in treatment of multidrug-resistant falciparum malaria. Antimicrob Agents Chemother. 1998;42:135-139.

39. Bakshi R, Hermeling-Fritz I, Gathmann I, Alteri E. An integrated assessment of the clinical safety of artemether-lumefantrine: a new oral fixed-dose combination antimalarial drug. Trans $R$ Soc Trop Med Hyg. 2000;94:419-424.

40. Bindschedler M, Lefèvre G, Ezzet F, Schaeffer N, Meyer I, Thomsen MS. Cardiac effects of co-artemether (artemether/ lumefantrine) and mefloquine given alone or in combination to healthy volunteers. Eur J Clin Pharmacol. 2000;56:375-381.

41. van Vugt M, Ezzet F, Nosten F, et al. No evidence of cardiotoxicity during antimalarial treatment with artemether-lumefantrine. Am J Trop Med Hyg. 1999;61:964-967.

42. Toovey S, Jamieson A. Audiometric changes associated with the treatment of uncomplicated falciparum malaria with co-artemether. Trans R Soc Trop Med Hyg. 2004;98:261-269.

43. Gürkov R, Eshetu T, Miranda IB, et al. Ototoxicity of artemether/ lumefantrine in the treatment of falciparum malaria: a randomized trial. Malar J. 2008;7:179.

44. Bate R, Tren R, Hess K, Attaran A. Physical and chemical stability of expired fixed dose combination artemether-lumefantrine in uncontrolled tropical conditions. Malar J. 2009;8:33.

45. Makanga M, Premji Z, Falade C, et al. Efficacy and safety of the six-dose regimen of artemether-lumefantrine in pediatrics with uncomplicated Plasmodium falciparum malaria: a pooled analysis of individual patient data. Am J Trop Med Hyg. 2006;74:991-998.

46. Mueller EA, van Vugt M, Kirch W, Andriano K, Hunt P, de Palacios PI. Efficacy and safety of the six-dose regimen of artemether-lumefantrine for treatment of uncomplicated Plasmodium falciparum malaria in adolescents and adults: a pooled analysis of individual patient data from randomized clinical trials. Acta Trop. 2006;100:41-53.
47. Piola P, Fogg C, Bajunirwe F, et al. Supervised versus unsupervised intake of six-dose artemether-lumefantrine for treatment of acute, uncomplicated Plasmodium falciparum malaria in Mbarara, Uganda: a randomised trial. Lancet. 2005;365:1467-1473.

48. Abdulla S, Sagara I, Borrmann S, et al. Efficacy and safety of artemether-lumefantrine dispersible tablets compared with crushed commercial tablets in African infants and children with uncomplicated malaria: a randomised, single-blind, multicentre trial. Lancet. 2008;372:1819-1827.

49. Juma EA, Obonyo CO, Akhwale WS, Ogutu BR. A randomized, open-label, comparative efficacy trial of artemether-lumefantrine suspension versus artemether-lumefantrine tablets for treatment of uncomplicated Plasmodium falciparum malaria in children in western Kenya. Malar J. 2008;7:262

50. Omari AA, Gamble C, Garner P. Artemether-lumefantrine (six-dose regimen) for treating uncomplicated falciparum malaria. Cochrane Database Syst Rev. 2005;(4):CD005564.

51. Bejon P, Lusingu J, Olotu A, et al. Efficacy of RTS,S/AS01E vaccine against malaria in children 5 to 17 months of age. $N$ Engl $J$ Med. 2008;359:2521-2532.

52. Sagara I, Rulisa S, Mbacham W, et al. Efficacy and safety of a fixed dose artesunate-sulphamethoxypyrazine-pyrimethamine compared to artemether-lumefantrine for the treatment of uncomplicated falciparum malaria across Africa: a randomized multi-centre trial. Malar $J$. 2009;8:63.

53. Kobbe R, Klein $\mathrm{P}$, Adjei $\mathrm{S}$, et al. A randomized trial on effectiveness of artemether-lumefantrine versus artesunate plus amodiaquine for unsupervised treatment of uncomplicated Plasmodium falciparum malaria in Ghanaian children. Malar J. 2008;7:261.

54. Karunajeewa HA, Mueller I, Senn M, et al. A trial of combination antimalarial therapies in children from Papua New Guinea. N Engl J Med. 2008;359:2545-2557.

55. Mens PF, Sawa P, van Amsterdam SM, et al. A randomized trial to monitor the efficacy and effectiveness by QT-NASBA of artemetherlumefantrine versus dihydroartemisinin-piperaquine for treatment and transmission control of uncomplicated Plasmodium falciparum malaria in western Kenya. Malar J. 2008;7:237.

56. Sagara I, Diallo A, Kone M, et al. A randomized trial of artesunatemefloquine versus artemether-lumefantrine for treatment of uncomplicated Plasmodium falciparum malaria in Mali. Am J Trop Med Hyg. 2008;79:655-661.

57. Adjei GO, Kurtzhals JA, Rodrigues OP, et al. Amodiaquineartesunate vs artemether-lumefantrine for uncomplicated malaria in Ghanaian children: a randomized efficacy and safety trial with one year follow-up. Malar J. 2008;7:127.

58. Owusu-Agyei S, Asante KP, Owusu R, et al. An open label, randomised trial of artesunate+amodiaquine, artesunate+chlorproguanil-dapsone and artemether-lumefantrine for the treatment of uncomplicated malaria. PLOS ONE. 2008;3:e2530.

59. Yeka A, Dorsey G, Kamya MR, et al. Artemether-lumefantrine versus dihydroartemisinin-piperaquine for treating uncomplicated malaria: a randomized trial to guide policy in Uganda. PLoS ONE. 2008;3: e2390.

60. Falade CO, Ogundele AO, Yusuf BO, Ademowo OG, Ladipo SM. High efficacy of two artemisinin-based combinations (artemetherlumefantrine and artesunate plus amodiaquine) for acute uncomplicated malaria in Ibadan, Nigeria. Trop Med Int Health. 2008;13: 635-643.

61. Kabanywanyi AM, Mwita A, Sumari D, Mandike R, Mugittu K, Abdulla S. Efficacy and safety of artemisinin-based antimalarial in the treatment of uncomplicated malaria in children in southern Tanzania. Malar J. 2007;6:146.

62. Zongo I, Dorsey G, Rouamba N, et al. Randomized comparison of amodiaquine plus sulfadoxine-pyrimethamine, artemether-lumefantrine, and dihydroartemisinin-piperaquine for the treatment of uncomplicated Plasmodium falciparum malaria in Burkina Faso. Clin Infect Dis. 2007;45:1453-1461. 
63. Thapa S, Hollander J, Linehan M, et al. Comparison of artemether-lumefantrine with sulfadoxine-pyrimethamine for the treatment of uncomplicated falciparum malaria in eastern Nepal. Am J Trop Med Hyg. 2007;77:423-430.

64. Sowunmi A, Gbotosho GO, Happi CT, et al. Therapeutic efficacy and effects of artemether-lumefantrine and amodiaquine-sulfalenepyrimethamine on gametocyte carriage in children with uncomplicated Plasmodium falciparum malaria in southwestern Nigeria. Am J Trop Med Hyg. 2007;77:235-241.

65. Mukhtar EA, Gadalla NB, El-Zaki SE, et al. A comparative study on the efficacy of artesunate plus sulphadoxine/pyrimethamine versus artemether-lumefantrine in eastern Sudan. Malar J. 2007;6:92.

66. Faye B, Ndiaye JL, Ndiaye D, Dieng Y, Faye O, Gaye O. Efficacy and tolerability of four antimalarial combinations in the treatment of uncomplicated Plasmodium falciparum malaria in Senegal. Malar J. 2007;6:80.

67. Kamya MR, Yeka A, Bukirwa H, et al. Artemether-lumefantrine versus dihydroartemisinin-piperaquine for treatment of malaria: a randomized trial. PLoS Clin Trials. 2007;2:e20.

68. Dorsey G, Staedke S, Clark TD, et al. Combination therapy for uncomplicated falciparum malaria in Ugandan children: a randomized trial. JAMA. 2007;297:2210-2219.

69. Ratcliff A, Siswantoro H, Kenangalem E, et al. Two fixed-dose artemisinin combinations for drug-resistant falciparum and vivax malaria in Papua, Indonesia: an open-label randomised comparison. Lancet. 2007;369:757-765.

70. Zongo I, Dorsey G, Rouamba N, et al. Artemether-lumefantrine versus amodiaquine plus sulfadoxine-pyrimethamine for uncomplicated falciparum malaria in Burkina Faso: a randomised non-inferiority trial. Lancet. 2007;369:491-498.

71. Fanello CI, Karema C, van Doren W, Van Overmeir C, Ngamije D, D'Alessandro U. A randomised trial to assess the safety and efficacy of artemether-lumefantrine (Coartem) for the treatment of uncomplicated Plasmodium falciparum malaria in Rwanda. Trans $R$ Soc Trop Med Hyg. 2007;101:344-350.

72. van den Broek I, Kitz C, Al Attas S, Libama F, Balasegaram M, Guthmann JP. Efficacy of three artemisinin combination therapies for the treatment of uncomplicated Plasmodium falciparum malaria in the Republic of Congo. Malar J. 2006;5:113.

73. Sagara I, Dicko A, Djimde A, et al. A randomized trial of artesunatesulfamethoxypyrazine-pyrimethamine versus artemether-lumefantrine for the treatment of uncomplicated Plasmodium falciparum malaria in Mali. Am J Trop Med Hyg. 2006;75:630-636.

74. Bukirwa H, Yeka A, Kamya MR, et al. Artemisinin combination therapies for treatment of uncomplicated malaria in Uganda. PLoS Clin Trials. 2006;1:e7.

75. Guthmann JP, Cohuet S, Rigutto C, et al. High efficacy of two artemisininbased combinations (artesunate + amodiaquine and artemether + lumefantrine) in Caala, Central Angola. Am J Trop Med Hyg. 2006;75: 143-145
76. Meremikwu M, Alaribe A, Ejemot R, et al. Artemether-lumefantrine versus artesunate plus amodiaquine for treating uncomplicated childhood malaria in Nigeria: randomized controlled trial. Malar J. 2006;5:43.

77. Mohamed AO, Eltaib EH, Ahmed OA, Elamin SB, Malik EM. The efficacies of artesunate-sulfadoxine-pyrimethamine and artemetherlumefantrine in the treatment of uncomplicated, Plasmodium falciparum malaria, in an area of low transmission in central Sudan. Ann Trop Med Parasitol. 2006;100:5-10.

78. Hutagalung R, Paiphun L, Ashley EA, et al. A randomized trial of artemether-lumefantrine versus mefloquine-artesunate for the treatment of uncomplicated multi-drug resistant Plasmodium falciparum on the western border of Thailand. Malar J. 2005;4:46.

79. Mårtensson A, Strömberg J, Sisowath C, et al. Efficacy of artesunate plus amodiaquine versus that of artemether-lumefantrine for the treatment of uncomplicated childhood Plasmodium falciparum malaria in Zanzibar, Tanzania. Clin Infect Dis. 2005;41:1079-1086.

80. van den Broek IV, Maung UA, Peters A, et al. Efficacy of chloroquine + sulfadoxine - pyrimethamine, mefloquine + artesunate and artemether + lumefantrine combination therapies to treat Plasmodium falciparum malaria in the Chittagong Hill Tracts, Bangladesh. Trans $R$ Soc Trop Med Hyg. 2005;99:727-735.

81. Koram KA, Abuaku B, Duah N, Quashie N. Comparative efficacy of antimalarial drugs including ACTs in the treatment of uncomplicated malaria among children under 5 years in Ghana. Acta Trop. 2005;95:194-203.

82. Sutherland CJ, Ord R, Dunyo S, et al. Reduction of malaria transmission to Anopheles mosquitoes with a six-dose regimen of co-artemether. PLoS Med. 2005;2:e92.

83. Mutabingwa TK, Anthony D, Heller A, et al. Amodiaquine alone, amodiaquine + sulfadoxine-pyrimethamine, amodiaquine + artesunate, and artemether-lumefantrine for outpatient treatment of malaria in Tanzanian children: a four-arm randomised effectiveness trial. Lancet. 2005;365:1474-1480.

84. Stohrer JM, Dittrich S, Thongpaseuth V, et al. Therapeutic efficacy of artemether-lumefantrine and artesunate-mefloquine for treatment of uncomplicated Plasmodium falciparum malaria in Luang Namtha Province, Lao People's Democratic Republic. Trop Med Int Health. 2004;9:1175-1183.

85. Mayxay $\mathrm{M}$, Khanthavong $\mathrm{M}$, Lindegårdh $\mathrm{N}$, et al. Randomized comparison of chloroquine plus sulfadoxine-pyrimethamine versus artesunate plus mefloquine versus artemether-lumefantrine in the treatment of uncomplicated falciparum malaria in the Lao People's Democratic Republic. Clin Infect Dis. 2004;39:1139-1147.

86. Lefèvre G, Looareesuwan S, Treeprasertsuk S, et al. A clinical and pharmacokinetic trial of six doses of artemether-lumefantrine for multidrug-resistant Plasmodium falciparum malaria in Thailand. Am J Trop Med Hyg. 2001;64:247-256.

87. van Vugt M, Looareesuwan S, Wilairatana P, et al. Artemetherlumefantrine for the treatment of multidrug-resistant falciparum malaria. Trans R Soc Trop Med Hyg. 2000;94:545-548.
Therapeutics and Clinical Risk Management

\section{Publish your work in this journal}

Therapeutics and Clinical Risk Management is an international, peerreviewed journal of clinical therapeutics and risk management, focusing on concise rapid reporting of clinical studies in all therapeutic areas, outcomes, safety, and programs for the effective, safe, and sustained use of medicines. This journal is indexed on PubMed Central, CAS,

\section{Dovepress}

EMBase, Scopus and the Elsevier Bibliographic databases. The manuscript management system is completely online and includes a very quick and fair peer-review system, which is all easy to use. Visit http://www.dovepress.com/testimonials.php to read real quotes from published authors. 